\title{
Performance of a domestic refrigerator using nanoparticles-based polyolester oil lubricant
}

\author{
M.E. Haque ${ }^{1,3}$, R.A. Bakar1, K. Kadirgama ${ }^{1}$, M.M. Noor ${ }^{1,2}$ and M. Shakaib ${ }^{3}$ \\ ${ }^{1}$ Faculty of Mechanical Engineering, Universiti Malaysia Pahang, \\ 26600 Pekan, Pahang, Malaysia \\ ${ }^{2}$ Department of Mechanical Engineering, University of Southern Queensland, Australia \\ ${ }^{3}$ NED University of Engineering and Technology, Karachi, Pakistan \\ Email rosli@ump.edu.my \\ Phone: +6094246239; Fax: +6094246222
}

\begin{abstract}
The performance of a domestic refrigerator with the addition of nanoparticles in the lubricant was experimentally investigated. Different sizes of nanoparticles of $\mathrm{Al}_{2} \mathrm{O}_{3}$ and $\mathrm{TiO}_{2}$ were added to the polyolester (POE) oil in two different volume concentrations $(0.05$ and $0.1 \mathrm{vol} . \%)$. Energy consumption tests and freeze capacity tests were then performed on the refrigerator. The investigation results showed that the refrigerator worked normally and safely with the nanolubricants. The results of the experiments indicated that the refrigerator performed better with nanolubricants as compared to pure POE oil. The COP of the systems was increased by $19 \%$ and $22 \%$ when $0.05 \%$ and $0.1 \% \mathrm{Al}_{2} \mathrm{O}_{3}$ nanoparticles were added to the POE oil respectively. The system with $0.1 \%$ volume concentration of $\mathrm{Al}_{2} \mathrm{O}_{3}$ and $\mathrm{TiO}_{2}$ nanoparticles added to the POE oil consumed $27.73 \%$ and $14.19 \%$ less energy as compared to the pure POE oil system. Hence, this study showed that the addition of nanoparticles in the lubricant oil of the refrigerator is practical and it enhanced the performance of the refrigerator
\end{abstract}

Keywords: Nanoparticle; Coefficient of performance; Refrigerator; Nanolubricant.

\section{INTRODUCTION}

Modern civilization depends heavily on a huge amount of energy for its existence [1]. The primary source of this energy is fossil fuels. Fifty percent of the global energy is derived from coal alone. The use of coal creates environmental concerns of global warming and $\mathrm{CO}_{2}$ emission [2-4]. The energy consumption by refrigeration and air conditioning systems for residential, commercial and industrial applications is increasing rapidly. In Malaysia, the energy consumed by refrigerators and air conditioners is estimated to be $26.3 \%$ of the total consumed [5]. Beside the global warming concern, another environmental concern faced by the refrigeration and air conditioning industry is the depletion of the ozone layer [6]. Ozone present in the stratospheric region absorbs ultraviolet rays from the sun and protects living things from exposure to ultraviolet radiation. Research has indicated that free chlorine radicals remove ozone from the atmosphere and that the ozone layer is therefore depleting.

A possible alternative solution to enhance the performance and improve the energy efficiency of a refrigerating system may come from nanotechnology. Nanofluids are defined as suspensions of nanometer size particles in a conventional base fluid [7-12]. 
The enhanced thermal conductivity of nanofluids has been a subject of intensive research for the past few decades [9, 13-18]. There are two different methods of applying nanofluids in a refrigerating system, namely nanorefrigerants and nanolubricants [19-21]. $\mathrm{Bi}$ et al. [22] performed an experiment on a domestic refrigerator. They used a nanolubricant made of mineral oil and $\mathrm{TiO}_{2}$ nanoparticles in the compressor and $\mathrm{R}-134 \mathrm{a}$ was used as the refrigerant. Their investigation showed a reduction in energy consumption by $21.2 \%$ as compared to the original R-134/POE oil system. Bi et al. [23] also investigated the performance of a domestic refrigerator which was originally using $\mathrm{R}$ 134a as refrigerant and polyolester oil as lubricant in the compressor. In the experiment, they substituted the POE oil with a mixture of $\mathrm{TiO}_{2} / \mathrm{Al}_{2} \mathrm{O}_{3}$ nanoparticles added into the mineral oil [24-26]. The results showed that the energy consumption of the system with $0.1 \%$ mass concentration of $\mathrm{TiO}_{2}$ nanolubricant was $26.1 \%$ less than the $\mathrm{R}-134 \mathrm{a}$ and POE oil system. Jwo et al. [27] replaced a R-134a/POE oil system with R12/MO and later added $\mathrm{Al}_{2} \mathrm{O}_{3}$ nanoparticles to the mineral oil (MO) to increase the lubricity and heat transfer performance. The results of the systems showed that the R12 system had a lower compression ratio as compared to the system with $\mathrm{R}-134 \mathrm{a}$ refrigerant. The system with $0.1 \mathrm{wt} \% \mathrm{Al}_{2} \mathrm{O}_{3}$ added to mineral oil had $2.4 \%$ less power consumption and a $4.4 \%$ higher coefficient of performance as compared to the R-134a and POE oil system. Peng et al. [28] investigated the impact of nanoparticles on the heat transfer characteristics of a refrigerant-based nanofluid, $\mathrm{CuO} / \mathrm{R} 113$, flowing inside a horizontal smooth tube. The experimental results showed that the heat transfer coefficient of the nanorefrigerant was greater than the pure refrigerant and the maximum enhancement was $29.7 \%$ for the coefficient of heat transfer. Henderson et al. [29] investigated the influence of $\mathrm{SiO}_{2}$ and $\mathrm{CuO}$ nanoparticles on the flow boiling of $\mathrm{R}-134 \mathrm{a}$ and $\mathrm{R}-134 \mathrm{a} /$ polyolester mixtures. The direct dispersion of $\mathrm{SiO}_{2}$ nanoparticles in $\mathrm{R}-134 \mathrm{a}$ resulted in a decrease of the heat transfer coefficient by as much as $55 \%$ compared to the pure R-134a. This degradation was partly due to the difficulties in obtaining a stable dispersion. But, on the other hand, excellent dispersion was achieved for a mixture of $\mathrm{R}-134 \mathrm{a} /$ polyolester with $\mathrm{CuO}$ nanoparticles and the heat transfer coefficient increased by more than $100 \%$ over the baseline R-134a/POE results. Bobbo et al. [30] investigated the tribology and solubility of R-134a in a mixture of commercial POE oil (SW32) with nanoparticles of $\mathrm{TiO}_{2}$ and single-wall carbon nanohorns (SWCNH). They performed the tribological tests and measured the solubility of R-134a at various temperatures. The investigation revealed that a small addition of nanoparticles to the base lubricant does not affect the tribological properties of the base lubricant. The study showed that the $\mathrm{POE} / \mathrm{TiO}_{2}$ mixture had the best performance compared with the pure POE and SWCNH/POE oil mixtures.

In refrigeration, air conditioning and heat pump systems, the boiling behaviour of the refrigerant and lubricant mixture is very important. The heat transfer characteristics of nucleate pool boiling of refrigerants are greatly affected by the lubricant. Generally, the addition of lubricants in the refrigerants degrades the pool boiling heat transfer. However, the amount of lubricant or oil in a refrigerating system is very small. Kedzierski [31] studied the pool boiling performance of $\mathrm{Al}_{2} \mathrm{O}_{3}$ nanoparticles with a mixture of $\mathrm{R}$ 134/polyolester. Nanoparticles of $\mathrm{Al}_{2} \mathrm{O}_{3}$ in three different volume fractions were mixed with polyolester lubricant and the mixture was added to R-134a in two different mass fractions. The study showed that the pool boiling heat transfer of R-134a can be increased by approximately $13 \%, 10 \%$ and $9 \%$ for different mixture concentrations. Only one concentration of the mixture showed an average heat transfer degradation of approximately $14 \%$ and this was believed to be due to nanoparticle agglomeration. 
The purpose of this article is to report the results obtained from experimental studies conducted on a domestic refrigerator. The experiments were conducted to show the ability of nanoparticles mixed in the POE oil to improve the power consumption of the compressor and enhance the heat transfer ability of the system. The coefficient of performance of the refrigerator with only POE oil as the lubricant in the compressor is also compared with the coefficient of performance of the system with two different nanoparticles added into the POE in different volume concentrations. In the present study, the refrigerant selected is $\mathrm{R}-134 \mathrm{a}$ and the nanoparticles are $\mathrm{Al}_{2} \mathrm{O}_{3}$ and $\mathrm{TiO}_{2}$.

\section{EXPERIMENTAL SETUP}

\section{Preparation of Nanolubricants}

The nanoparticles added to the base fluid of POE oil were $\mathrm{Al}_{2} \mathrm{O}_{3}$, and $\mathrm{TiO}_{2}$. The volume concentration $(\phi)$ of nanofluids can be estimated from Eq. (1) [32]. For a known volume concentration, and using the density from Table 1, Eq. (1) can be used to estimate the mass of nanoparticles. The required mass of the nanoparticles corresponding to the volume concentrations was measured accurately with the help of a precision electronic balance, as shown in Figure 1(a). The source and physical properties of the nanoparticles are given in Table 1.

$$
\emptyset=\left(\frac{m_{p}}{\rho_{p}}\right) /\left(\frac{m_{p}}{\rho_{p}}+\frac{m_{b f}}{\rho_{b f}}\right) \times 100
$$

Table 1. Thermophysical properties of nanoparticles.

\begin{tabular}{lllll}
\hline Nanoparticles & $\begin{array}{l}\text { Size } \\
\text { (nm) }\end{array}$ & $\begin{array}{l}\text { Thermal conductivity } \\
(\mathrm{W} / \mathrm{m} \mathrm{K})\end{array}$ & $\begin{array}{l}\text { Density } \\
\left(\mathrm{kg} / \mathrm{m}^{3}\right)\end{array}$ & $\begin{array}{l}\text { Specific heat } \\
(\mathrm{J} / \mathrm{kg} \mathrm{K})\end{array}$ \\
\hline $\mathrm{Al}_{2} \mathrm{O}_{3}$ & 40 to 80 & $36.0[33]$ & 3700 & 773 \\
$\mathrm{TiO}_{2}$ & 25 & $8.4[33]$ & 3900 & 692 \\
$\mathrm{POE}$ oil & & & 840 & \\
\hline
\end{tabular}

Source: Data from manufacturer [33]

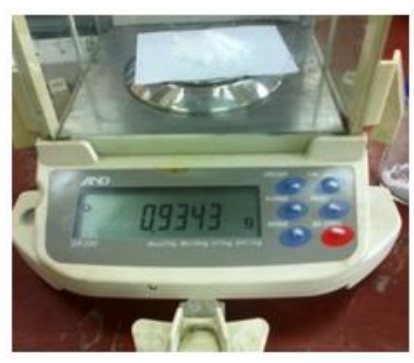

(a)

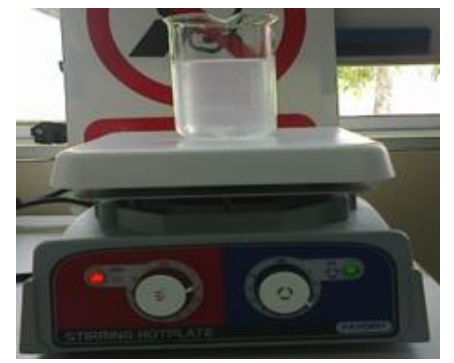

(b)

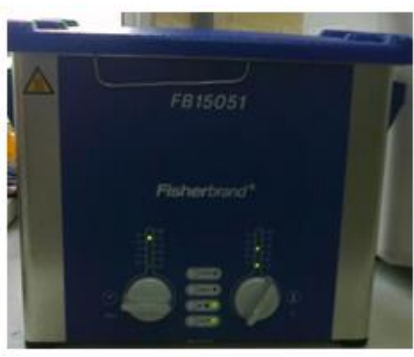

(c)

Figure 1. Equipment used in the experimental work: (a) Electronic balance, (b) stirring hotplate, (c) ultrasonic homogenizer.

The nanolubricants were prepared by a two-step method [34, 35]. The mass of nanoparticles for the $0.05 \%$ and $0.1 \%$ volume concentrations was added to the POE oil and the mixtures were stirred on a magnetic stirrer (Figure 1(b)) for two hours. The mixtures were then kept vibrating in an ultrasonic homogenizer (Figure 1(c)) for half an 
hour to fully separate the nanoparticles and to prevent agglomeration and sedimentation of particles. No surfactant was added to the mixtures, as it can change the thermophysical properties of the nanolubricants. The nanolubricants were observed for sedimentation for 48 hours. Agglomeration or sedimentation did not occur and the nanolubricants were stable during the observations, which could be due to the low volume concentrations of the nanoparticles [36, 37].

\section{System Evacuation}

In order to remove incondensable substances such as air, water, moisture and inert gases from the refrigeration system, the evacuation process is used. A vacuum pump and a charging manifold is the most common equipment used for evacuation. A Robinair model 15601 vacuum pump and a three-hose charging manifold with low-side and high- side pressure gauges is used in this experiment to evacuate the system. The high-side pressure hose was kept closed all the time and the low-side hose was connected to the service port (Schrader valve) of the compressor, while the middle hose, which is also called the service hose, was attached to the vacuum pump as shown in Figure 2.

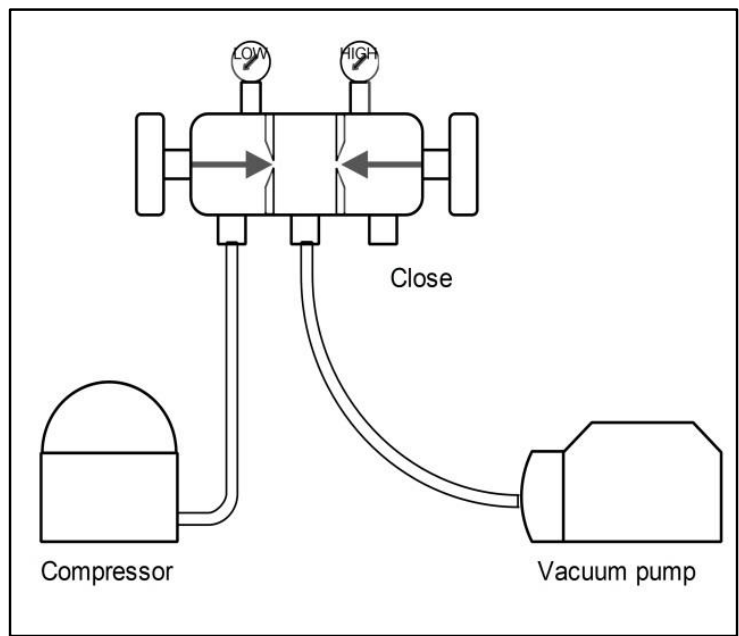

(a)

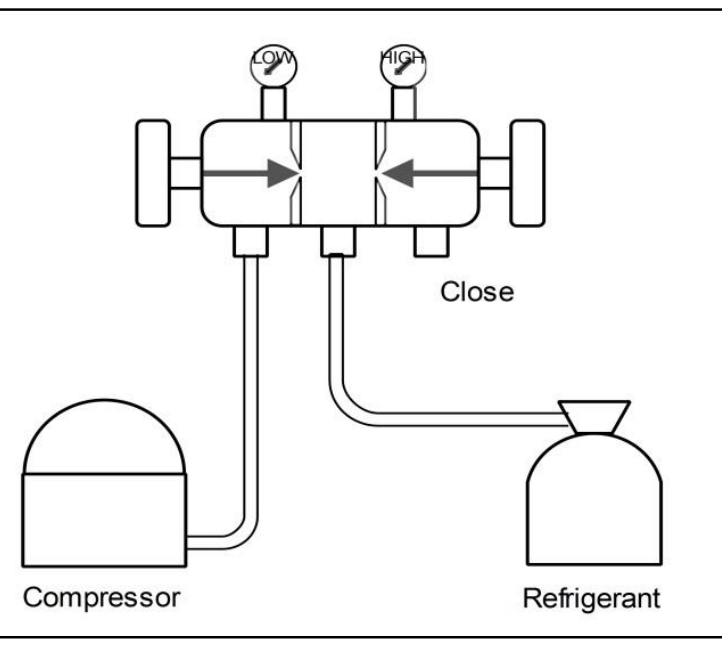

(b)

Figure 2. System evacuation and charging process.

\section{System Charging}

Table 2 shows the technical specification of the refrigerator which is used as part of the experimental rig. The refrigerator (Figure 3) can be fully charged with $120 \mathrm{~g}$ of refrigerant $\mathrm{R}-134 \mathrm{a}$. The refrigerant can be charged into the system in either vapour or liquid form. There are different methods to accurately charge the system with the right amount of refrigerant. It can be charged by weight, by observing the sight glass and pressure and by monitoring the current load. There are also automatic digital charging systems available from different manufacturers that can charge the required amount accurately and automatically. Charging by weight is one of the most accurate and fastest methods of charging a known amount of refrigerant into the system. In this experiment, charging of refrigerant vapour is done with help of an electronic weighing machine, although observations through the pressure gauges and sight glass were also made. 
Table 2. Specifications of the refrigerator (Panasonic, Model NR-BK265).

\begin{tabular}{ll}
\hline Description & Specifications \\
\hline Gross capacity & $234 \mathrm{~L}$ \\
Freezer compartment & $75 \mathrm{~L}$ \\
Fresh food compartment & $159 \mathrm{~L}$ \\
Outside dimensions (mm) & $600 \times 614 \times 1449$ \\
Refrigerant type & HFC-134a \\
Charged mass & $120 \mathrm{~g}$ \\
Compressor type & Recip. hermetically sealed \\
Compressor oil charge & $195 \mathrm{ml}$ \\
Power source & $\mathrm{AC} 240 / 50 \mathrm{~Hz}$ \\
Weight & $43 \mathrm{~kg}$ \\
\hline
\end{tabular}

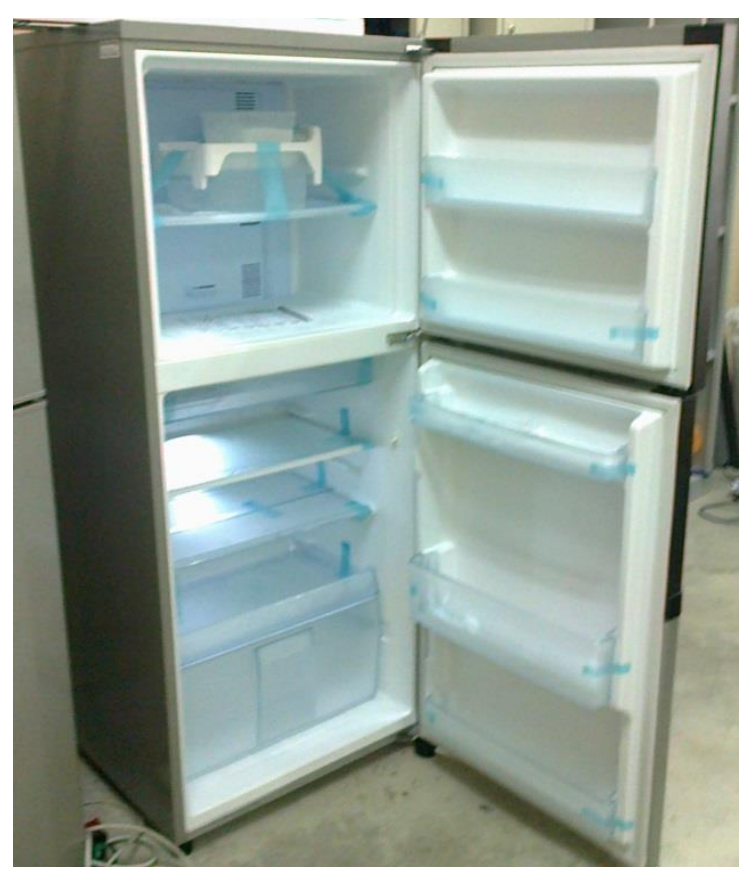

Figure 3. Refrigerator.

\section{Experimental Apparatus}

All the experiments were carried out in a room where the room temperature was $28{ }^{\circ} \mathrm{C}$ and the humidity level was above $70 \%$. A domestic 234 litre capacity, double door, nofrost refrigerator was used. The refrigerator specifications are listed in Table 2. It was originally designed to work with R-134a refrigerant and POE oil as lubricant in the compressor. Twenty-four k-type thermocouples were used to measure the temperature of the air inside the refrigerator. The temperature of the refrigerant at suction and discharge of the compressor, and the temperature of the condenser were also recorded (Figure 4(a),(b)). The thermocouple readings were recorded by data loggers. Two pressure transducers were placed at the suction and discharge ports of the compressor with the respective data logger to record the pressure fluctuations. The power consumption of the compressor was measured by a clamp-on wattmeter (Power Analyzer, Lutron DW-6092) with $0.01 \mathrm{kWh}$ resolution. Table 3 gives the detailed specifications of the test 
instrumentation. An electronic balance was used to charge the exact amount of the refrigerant into the system.
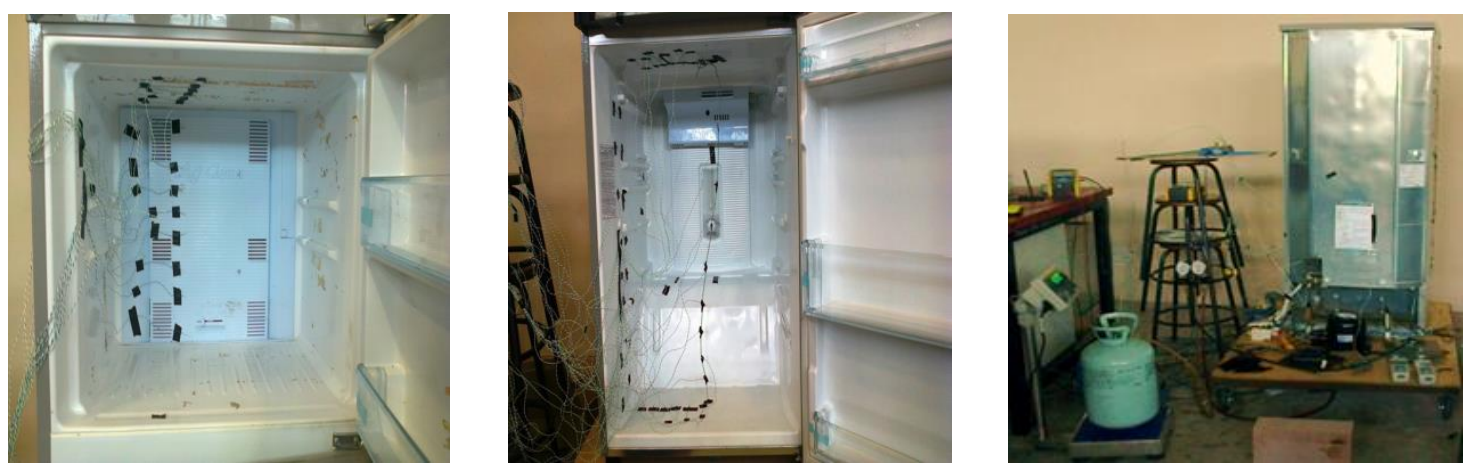

Figure 4. Experimental rig: (a) freezer thermocouples, (b) refrigerator thermocouples, (c) instrumentation.

Table 3. Measurement equipment specification.

\begin{tabular}{|c|c|c|c|}
\hline Variable & Device & Range & Accuracy \\
\hline & K type thermocouples & -75 to 250 & $\pm\left(0.4 \%+1{ }^{\circ} \mathrm{C}\right)$ \\
\hline Temperature & $\begin{array}{l}\text { With 26-channel temperature } \\
\text { recorder }\end{array}$ & ${ }^{\circ} \mathrm{C}$ & \\
\hline & Pressure sensor PS100-20 bar & 0 to 20 bar & $\pm(0.5 \%+1 \mathrm{~d})$ \\
\hline Pressure & $\begin{array}{l}\text { Pressure sensor PS100-5 bar } \\
\text { with pressure meter }\end{array}$ & 0 to 5 bar & \\
\hline Power & 3-phase power analyzer & $\begin{array}{l}0.000 \text { to } \\
9.999 \mathrm{kWH}\end{array}$ & $\begin{array}{l} \pm(2 \%+0.008 \\
\mathrm{kWH})\end{array}$ \\
\hline
\end{tabular}

\section{Experimental Procedure}

A first performance of the refrigerator was recorded with the R-134a as the refrigerant in the refrigerant circuit and POE oil as the lubricant in the compressor. The data for temperature, pressure and energy consumption were recorded twice, once for the freezer compartment and then for the refrigerator compartment. This result is used as the base data for comparison. Secondly, four different previously made nanolubricants of two different nanoparticles $\left(\mathrm{Al}_{2} \mathrm{O}_{3}, \mathrm{TiO}_{2}\right)$ and two different volume concentrations $(0.05 \%$ and $0.1 \%$ ) were added one by one into the compressor. For each of the four samples of nanolubricant, the refrigerator was tested to investigate the effect of the nanoparticles properties on its performance. Every time, after charging of the refrigerant and lubricant, the refrigerator was allowed to stabilize for 30 minutes.

The refrigerator was placed on a $3 \times 4$ feet wooden frame with four wheels underneath it (Figure 4(c)). The compressor was pulled out from the refrigerator and fixed on the wooden frame. The refrigerant circuit was rebuilt with four T-connectors. Two Tconnectors were used for the suction and discharge pressure sensors and two T-connectors were used for the suction and discharge side temperature of the refrigerant. The refrigerant and lubricant masses added during the performance tests were strictly measured and controlled. A Schrader valve was welded to the service port of the compressor to charge it with the lubricant and refrigerant. At the end of each test the compressor was disconnected from the refrigerant circuit and the lubricant was discharged through the 
suction port and collected in a container. High-pressure gas was used to make sure that all the lubricant from the compressor was pushed out.

\section{RESULTS AND DISCUSSION}

Extensive experiments have been conducted on the refrigerator rig for its performance improvement. The results of the experiments are discussed below. Figure 5 shows the variation of cooling load temperature with time for pure POE oil and POE oil mixed with $0.05 \%$ and $0.1 \%$ nanoparticles of $\mathrm{Al}_{2} \mathrm{O}_{3}$ and $\mathrm{TiO}_{2}$. In both cases, the nanolubricant performance is better than the pure POE oil. It can be seen that the time required to reduce the cooling load temperature is the least with $\mathrm{Al}_{2} \mathrm{O}_{3}$ nanoparticles [23]. From Figure 5(b) it can be observed that the time required to reduce the cooling load temperature from -1 ${ }^{\circ} \mathrm{C}$ to $-6{ }^{\circ} \mathrm{C}$ is 25 minutes for POE oil, while it takes only 10 minutes for the POE oil with $0.05 \%$ of $\mathrm{Al}_{2} \mathrm{O}_{3}$ and $\mathrm{TiO}_{2}$ nanoparticles. In the case of a refrigerator, the lubricant used in the compressor is mixed with the refrigerant and travels through the refrigerating circuit. As compared to POE oil, which acts as an insulator in the refrigerant circuit and hinders the heat transfer, the high thermal conductivity of the nanolubricant facilitates more effective heat transfer, and therefore increases the speed of reducing the cooling load temperature [38].

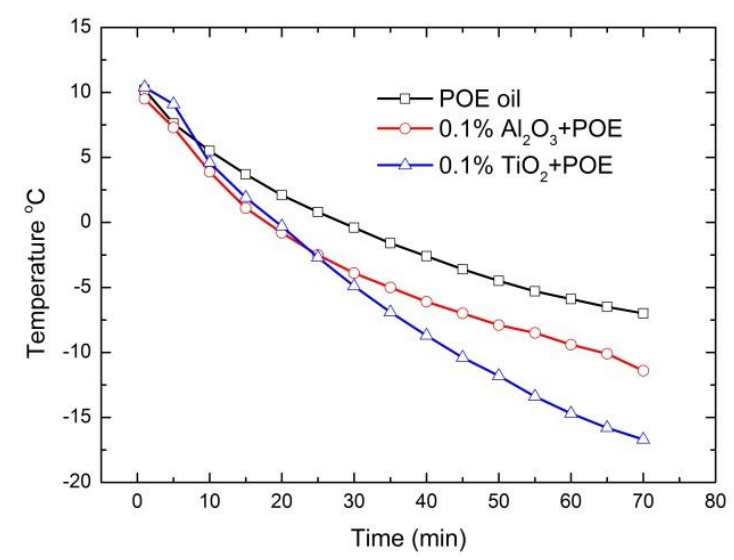

(a)

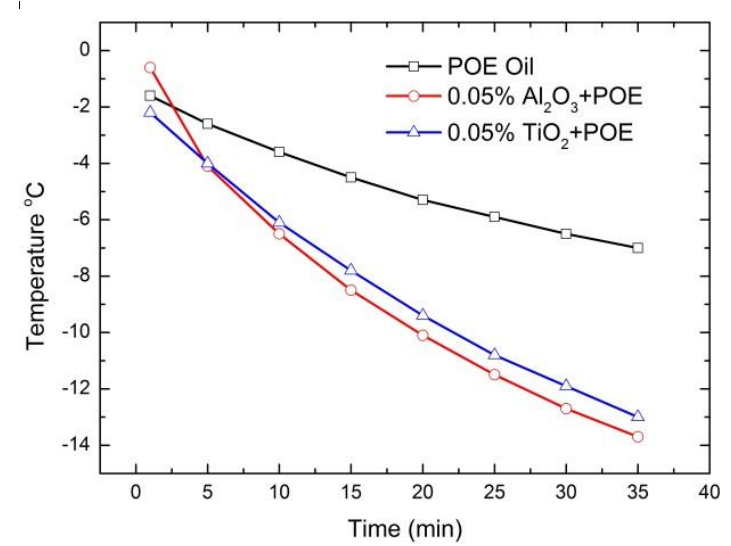

(b)

Figure 5. Temperature-time history for freezer compartment.

Freezing capacity is a standard test for refrigerators [39]. It is evaluated by the time taken to reduce the temperature in the freezer compartment from a positive temperature to a negative temperature under specified conditions. From Figure 6(a) it is evident that the freezing capacity of POE oil with $0.1 \% \mathrm{TiO}_{2}$ nanoparticles is higher than the other two systems. It takes about 35 minutes for the system with POE oil containing $0.1 \% \mathrm{TiO}_{2}$ to reduce the cooling load temperature from $10^{\circ} \mathrm{C}$ to $-7^{\circ} \mathrm{C}$, which is $50 \%$ less than the pure POE oil system. This enhancement in achieving faster cooling is due to the fact that the nanoparticles present in the refrigerant improve the heat transfer rate of the refrigerant in the evaporator. In Figure 6(b), the freezing capacity of $0.05 \%$ of $\mathrm{Al}_{2} \mathrm{O}_{3}$ is $60 \%$ less than the pure POE oil system. This improvement is due to the presence of nanoparticles in the refrigerating circuit [38]. The lubricating oil of the compressor travels with the refrigerant into the entire refrigerant circuit. The nanoparticles also reach the inside surface of the evaporator along with the oil. The presence of these nanoparticles 
enhances the heat transfer of the evaporator [40] and therefore reduces the freezing capacity of the refrigerator.

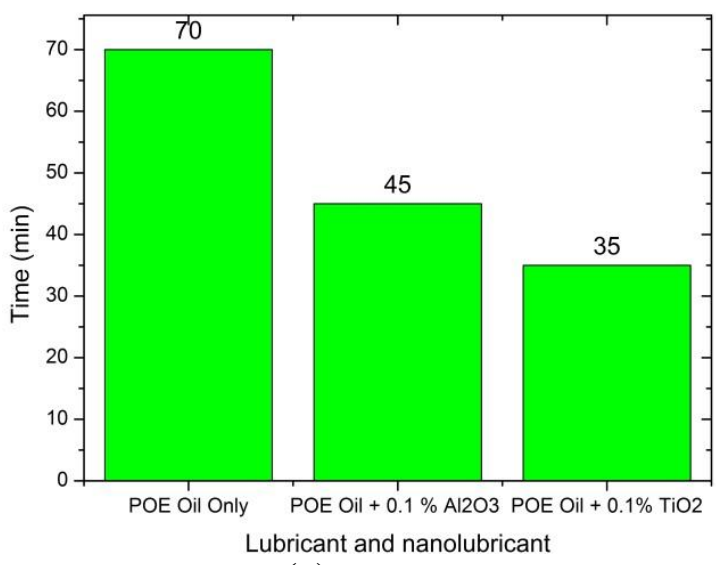

(a)

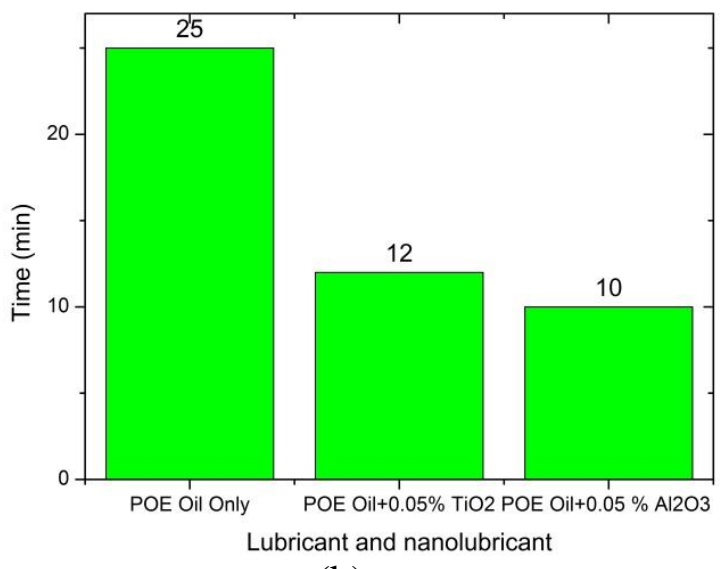

(b)

Figure 6. Nanoparticles influence on freezing capacity.

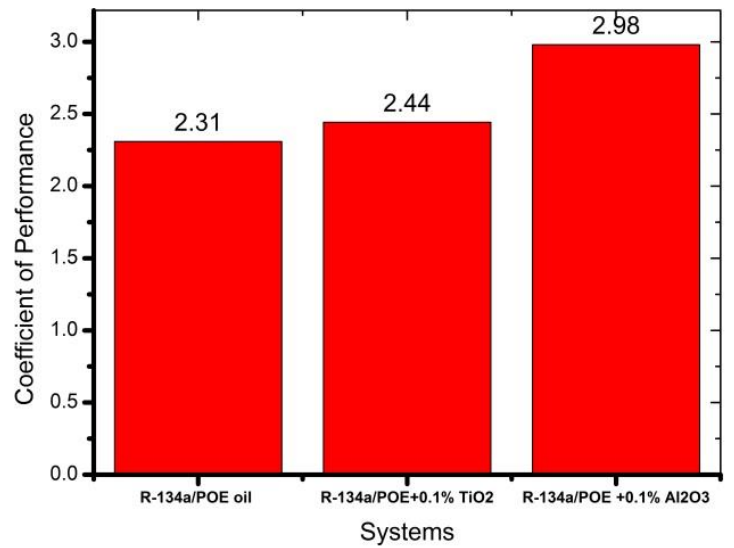

(a)

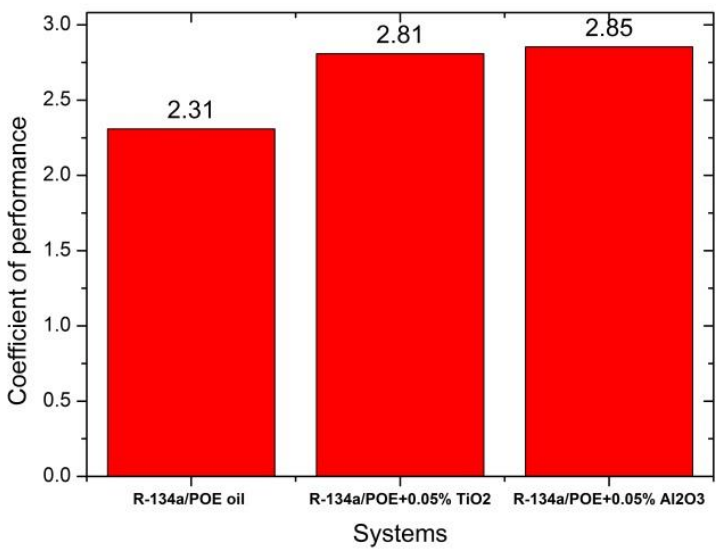

(b)

Figure 7. Comparison of coefficient of performance.

Figure 7 shows histograms for the COP of all the systems. The graphs show that all the systems with nanoparticles added to their lubricant had higher COP values. The system with the $0.05 \% \mathrm{Al}_{2} \mathrm{O}_{3}$ added to the POE oil has a COP which is $19 \%$ higher than the POE oil systems. Similarly, $0.1 \% \mathrm{Al}_{2} \mathrm{O}_{3}$ nanoparticles by volume when added to POE oil produce a COP which is $22 \%$ higher than the pure POE oil system. The increase in the coefficient of performance of the refrigerator with nanolubricant can be explained by considering the improved tribology and thermal conductivity caused by the nanoparticles in the lubricant oil. The investigation by [41] showed that the addition of fullerene $\mathrm{C}_{60}$ nanoparticles in the mineral oil decreases the friction coefficients as compared to pure mineral oil. The friction coefficient of the lubricating oil is directly related to the power consumption of the compressor as the addition of nanoparticles decreases the friction coefficient of the lubricating oil, which results in a decrease of energy consumption by the compressor and therefore improves the COP of the refrigerator. The experiment conducted by [42] on the tribological properties of a lubricating oil with added nanoparticles showed that the nanoparticles first adsorbed on the wear scar surface, which 
helped to form an amorphous film due to the shearing effect. This anti-wear film reduces the frictional power loss due to a reduction in the friction between the contact surfaces.

Increase in the thermal conductivity of the nanolubricant is one of the key reasons for the improved coefficient of performance of the refrigerator. Dispersion of nanoparticles in the lubricating oil increases the thermal conductivity of the lubricant. Although many theories have been put forward by researchers to explain the mechanism behind the increase in thermal conductivity [43], so far none can fully explain it. Brownian motion is considered to be one of the major mechanisms for enhanced thermal conductivity. The high interaction between the nanoparticles and base fluid molecules induces micro-convection. Smaller nanoparticles have a higher surface area, which increases the number of interactions and hence leads to the enhanced thermal conductivity of nanofluids.

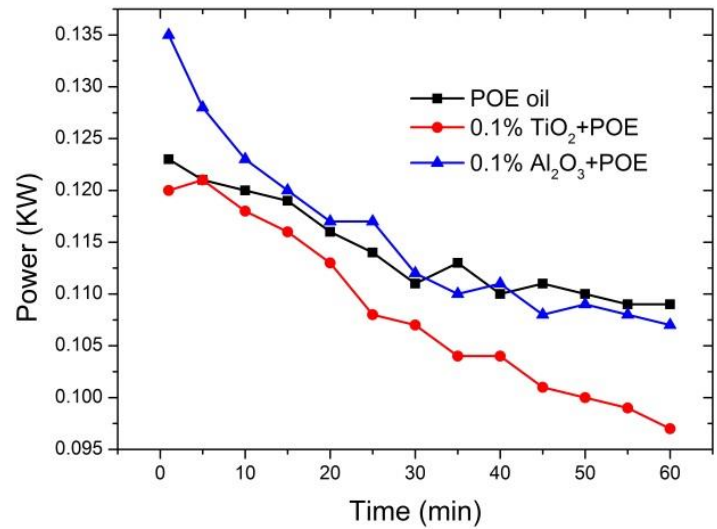

(a)

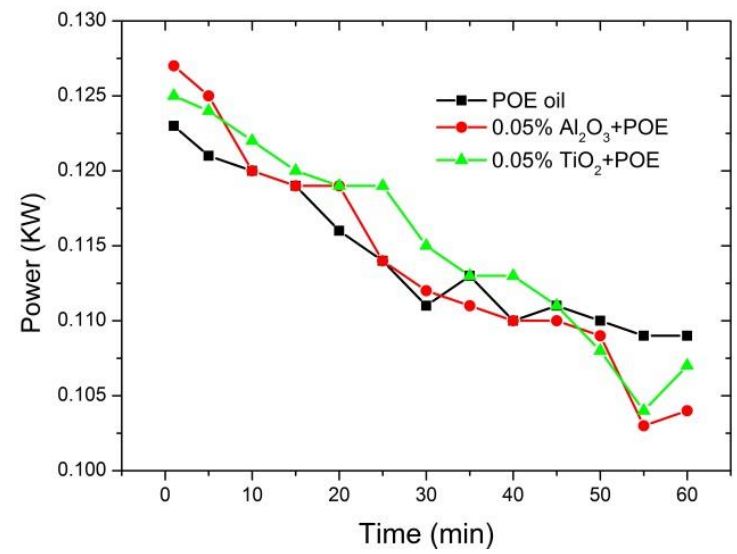

(b)

Figure 8. Power consumption of all systems.

Figure 8 shows the power consumption for all the systems. The effectiveness of the nanolubricants can be observed clearly from the power consumption of the compressor. The trend of the graph shows that the overall power consumption of the systems with nanoparticles mixed in the POE oil is better than the pure POE oil system. The decrease in compressor power consumption is due to the lower friction and better lubricity of the nanolubricants [42]. This is similar to the analysis by Bi et al. [44], who reported a $9.6 \%$ reduction in the power consumption for a refrigeration system using $\mathrm{R}$ $600 \mathrm{a} /$ mineral oil with $\mathrm{TiO}_{2}$ nanoparticles as compared to an $\mathrm{R}-600 \mathrm{a} / \mathrm{POE}$ oil system. The experimental results strongly suggest that the addition of nanoparticles in small quantities is an effective means to reduce the power consumption of the compressor.

Figure 9 shows the energy performance comparison for all systems. It can be clearly observed that the energy consumption is considerably lower when nanolubricants are used in the compressor. The reduction in energy consumption is $27.73 \%$ when $0.1 \%$ $\mathrm{Al}_{2} \mathrm{O}_{3}$ nanoparticles is mixed with $\mathrm{POE}$ oil and $14.19 \%$ when the same volume concentration of $\mathrm{TiO}_{2}$ is used with POE oil. Bi et al. [23] reported that the energy of a refrigerator can be reduced by $26.1 \%$ when $0.1 \% \mathrm{TiO}_{2}$ nanoparticles are added into the mineral oil lubricant instead of the POE oil. The reduction in energy consumption is due to the tribological improvement caused by the addition of nanoparticles in the POE oil. Nanoparticles reduce the wear rate and coefficient of friction between moving surfaces, which is directly related to the energy consumption of the compressor. A comparison of the present work with that of other researchers is presented in Table 4. 


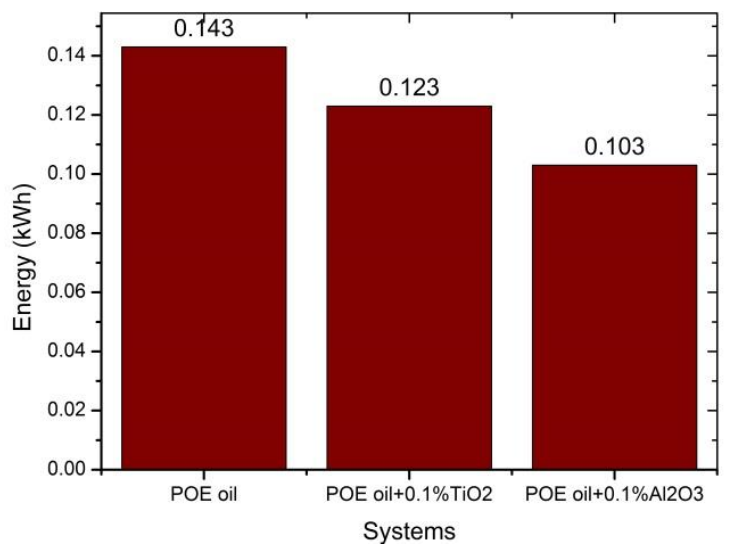

(a)

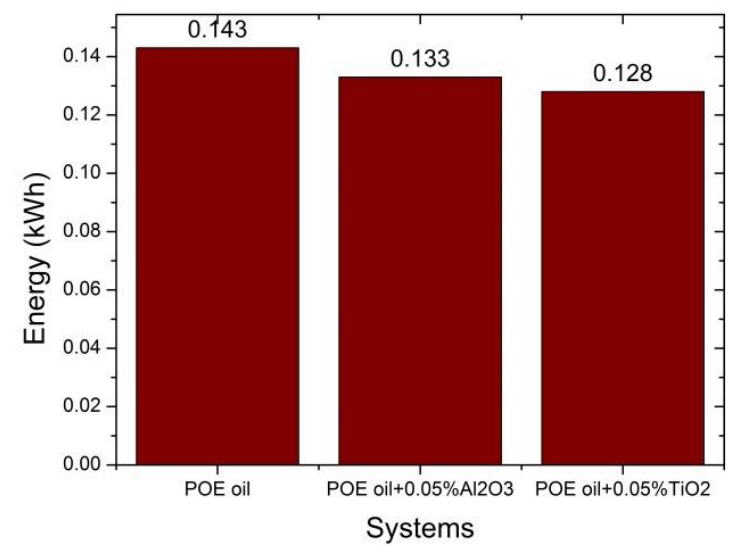

(b)

Figure 9. Energy performance of all systems.

Table 4. Comparison table for performance improvement of refrigeration systems.

\begin{tabular}{|c|c|c|c|c|c|}
\hline Researcher & $\begin{array}{l}\text { Refrigerant, } \\
\text { lubricant and } \\
\text { nanoparticles }\end{array}$ & $\begin{array}{l}\text { Power } \\
\text { (saving) }\end{array}$ & $\begin{array}{l}\text { Energy } \\
\text { (saving) }\end{array}$ & $\begin{array}{l}\text { COP } \\
\text { (improve } \\
\text {-ment) }\end{array}$ & $\begin{array}{l}\text { Freezing velocity } \\
\text { (higher speed) }\end{array}$ \\
\hline Bi et al. [22] & $\mathrm{R}-134 \mathrm{a} / \mathrm{POE} / \mathrm{TiO}_{2}$ & & $7.43 \%$ & & \\
\hline Bi et al. [23] & $\mathrm{R}-134 \mathrm{a} / \mathrm{MO} / \mathrm{TiO}_{2}$ & & $26 \%$ & & \\
\hline Jwo et al. [27] & $\mathrm{R}-12 / \mathrm{MO} / \mathrm{Al}_{2} \mathrm{O}_{3}$ & $2.4 \%$ & & & \\
\hline Bi et al. [44] & $\mathrm{R}-600 \mathrm{a} /-/ \mathrm{TiO}_{2}$ & & $5.94 \%$ & & $9.6 \%$ \\
\hline Subramani and & R-134a/ & & $25 \%$ & & \\
\hline Prakash [45] & $\mathrm{POE} / \mathrm{Al}_{2} \mathrm{O}_{3}$ & & & & \\
\hline $\begin{array}{l}\text { Sabreesh et al. } \\
\text { [36] }\end{array}$ & $\mathrm{R}-12 / \mathrm{MO} / \mathrm{TiO}_{2}$ & & & $17 \%$ & \\
\hline Kumar and & R-134a/ & & $10.32 \%$ & increased & \\
\hline Elansezhian [46] & $\mathrm{PAG} / \mathrm{Al}_{2} \mathrm{O}_{3}$ & & & & \\
\hline Present research & $\begin{array}{l}\mathrm{R}-134 \mathrm{a} / \\
\mathrm{POE} / \mathrm{Al}_{2} \mathrm{O}_{3}\end{array}$ & & $27.73 \%$ & $22.50 \%$ & increased \\
\hline Present research & $\mathrm{R}-134 \mathrm{a} / \mathrm{POE} / \mathrm{TiO}_{2}$ & & $14.19 \%$ & $17.78 \%$ & increased \\
\hline
\end{tabular}

\section{CONCLUSIONS}

In this paper, the application of nanoparticles in a refrigerator has been investigated to take advantage of the anomalous increase in heat transfer caused by the suspension of nanosize particles in a fluid. A domestic refrigerator has been modified and used as a test rig to perform several tests to evaluate its performance with the nanolubricants. The temperature, pressure and energy data from the system consisting of R-134a as refrigerant and POE oil as lubricant in the compressor have been recorded as the base data. Four nanolubricants were prepared by adding $0.05 \%$ and $0.1 \%$ volume concentrations of nanoparticles of $\mathrm{Al}_{2} \mathrm{O}_{3}$ and $\mathrm{TiO}_{2}$ into POE oil. The experimental data from the systems comprising refrigerant R-134a and POE oil with volume concentrations of nanoparticles added to it, are compared with the base data. The following conclusions can be drawn from the present study. 
i). Nanoparticles enhanced the heat transfer in the evaporator, which resulted in faster achievement of the cooling load.

ii). The freezing capacity of the refrigerator is higher when nanolubricants are used in the compressor as compared to the POE oil system.

iii). The power consumption of the compressor is reduced when nanolubricants are used instead of pure POE oil. As compared to the pure POE oil system, the energy consumption of the refrigerator reduces by $27.73 \%$ when $0.1 \% \quad \mathrm{Al}_{2} \mathrm{O}_{3}$ nanoparticles is mixed with the POE oil and a $14.19 \%$ reduction is achieved with $\mathrm{TiO}_{2}$ nanolubricant.

iv). The coefficient of performance of the refrigerator increases by $19 \%$ and $22 \%$ when two different $\mathrm{Al}_{2} \mathrm{O}_{3}$ nanolubricants are used respectively.

\section{ACKNOWLEDGEMENTS}

The authors would like to be obliged to Universiti Malaysia Pahang for providing laboratory facilities and financial assistance under project no. GRS 140311.

\section{REFERENCES}

[1] Allouhi A, El Fouih Y, Kousksou T, Jamil A, Zeraouli Y, Mourad Y. Energy consumption and efficiency in buildings: current status and future trends. Journal of Cleaner Production. 2015.

[2] Bilgen S. Structure and environmental impact of global energy consumption. Renewable and Sustainable Energy Reviews. 2014;38:890-902.

[3] Nejat P, Jomehzadeh F, Taheri MM, Gohari M, Abd. Majid MZ. A global review of energy consumption, $\mathrm{CO}_{2}$ emissions and policy in the residential sector (with an overview of the top ten $\mathrm{CO}_{2}$ emitting countries). Renewable and Sustainable Energy Reviews. 2015;43:843-62.

[4] Yin X, Chen W, Eom J, Clarke LE, Kim SH, Patel PL, et al. China's transportation energy consumption and $\mathrm{CO}_{2}$ emissions from a global perspective. Energy Policy. 2015;82:233-48.

[5] Mahlia TMI, Masjuki HH, Saidur R, Amalina MA. Cost-benefit analysis of implementing minimum energy efficiency standards for household refrigeratorfreezers in Malaysia. Energy Policy. 2004;32:1819-24.

[6] Wongwises S, Chimres N. Experimental study of hydrocarbon mixtures to replace HFC-134a in a domestic refrigerator. Energy Conversion and Management. 2005;46:85-100.

[7] Choi SUS, Eastman JA. Enhancing thermal conductivity of fluids with nanoparticles; 1995.

[8] Sahid NSM, Rahman MM, Kadirgama K. Neural network modeling of grinding parameters of ductile cast iron using minimum quantity lubrication. International Journal of Automotive and Mechanical Engineering. 2015;11:2608-21.

[9] Ghafoori M, Ghobadian B, Najafi G, Layeghi M, Rashidi A, Mamat R. Effect of nano-particles on the performance and emission of a diesel engine using biodieseldiesel blend. International Journal of Automotive and Mechanical Engineering. 2015;12:3097-108.

[10] Suriati G, Mariatti M, Azizan A. Synthesis of silver nanoparticles by chemical reduction method: Effect of reducing agent and surfactant concentration. 
International Journal of Automotive and Mechanical Engineering. 2014;10:19207.

[11] Yogeswaran M, Kadirgama K, Rahman MM, Devarajan R, Noor MM. Effect of $\mathrm{ZnO}$ nano materials on grinding surface finishing. International Journal of Automotive and Mechanical Engineering. 2015;12:2829-43.

[12] Yogeswaran M, Kadirgama K, Rahman MM, Devarajan R. Temperature analysis when using ethylene-glycol-based $\mathrm{TiO}_{2}$ as a new coolant for milling. International Journal of Automotive and Mechanical Engineering. 2015;11:2272-81.

[13] Das SK, Choi SUS, Patel HE. Heat transfer in nanofluids-A review. Heat Transfer Engineering. 2006;27:3-19.

[14] Wang XQ, Mujumdar AS. Heat transfer characteristics of nanofluids: a review. International Journal of Thermal Sciences. 2007;46:1-19.

[15] $\mathrm{Wu} \mathrm{JM}$, Zhao J. A review of nanofluid heat transfer and critical heat flux enhancement-Research gap to engineering application. Progress in Nuclear Energy. 2013;66:13-24.

[16] Nambeesan KPV, Parthiban R, Ram Kumar K, Athul UR, Vivek M, Thirumalini $\mathrm{S}$. Experimental study of heat transfer enhancement in automobile radiator using $\mathrm{Al}_{2} \mathrm{O}_{3}$ /water-ethylene glycol nanofluid coolants. International Journal of Automotive and Mechanical Engineering. 2015;12:2857-65.

[17] Ismail AR, Abdullah SNA, Abdullah AA, Deros BM. A Descriptive analysis of factors contributing to bus drivers' performances while driving: A case study in Malaysia. International Journal of Automotive and Mechanical Engineering. 2015;11:2430-7.

[18] Abdolbaqi MK, Azwadi CSN, Mamat R, Azmi WH, Najafi GN. Nanofluids heat transfer enhancement through straight channel under turbulent flow. International Journal of Automotive and Mechanical Engineering. 2015;11:2294-305.

[19] Saidur R, Kazi SN, Hossain MS, Rahman MM, Mohammed HA. A review on the performance of nanoparticles suspended with refrigerants and lubricating oils in refrigeration systems. Renewable and Sustainable Energy Reviews. 2011;15:31023.

[20] Yusof TM, Arshad AM, Suziyana MD, Chui LG, Basrawi MF. Experimental study of a domestic refrigerator with $\mathrm{POE}-\mathrm{Al}_{2} \mathrm{O}_{3}$ nanolubricant. International Journal of Automotive and Mechanical Engineering. 2015;11:2243-52.

[21] Fadhillahanafi NM, Leong KY, Risby MS. Stability and Thermal Conductivity Characteristics of Carbon Nanotube based Nanofluids. International Journal of Automotive and Mechanical Engineering. 2013;8:1376-84.

[22] Shengshan B, Lin S. Experimental investigation of a refrigerator with a nanorefrigerant $[\mathrm{J}]$. Journal of Tsinghua University (Science and Technology). 2007;11:016.

[23] Bi SS, Shi L, Zhang L-l. Application of nanoparticles in domestic refrigerators. Applied Thermal Engineering. 2008;28:1834-43.

[24] Abdul Hamid K, Azmi WH, Mamat R, Usri NA, Najafi G. Effect of temperature on heat transfer coefficient of titanium dioxide in ethylene glycol-based nanofluid. Journal of Mechanical Engineering and Sciences. 2015;8:1367-75.

[25] Hussein AM, Sharma KV, Bakar RA, Kadirgama K. Heat transfer enhancement with nanofluids - A Review. Journal of Mechanical Engineering and Sciences. 2013;4:452-61. 
[26] Azmi WH, Sharma KV, Mamat R, Anuar S. Nanofluid properties for forced convection heat transfer: An overview. Journal of Mechanical Engineering and Sciences. 2013;4:397-408.

[27] Jwo C-S, Jeng L-Y, Teng T-P, Chang H. Effects of nanolubricant on performance of hydrocarbon refrigerant system. Journal of Vacuum Science and Technology B: Microelectronics and Nanometer Structures. 2009;27:1473-7.

[28] Peng H, Ding G, Jiang W, Hu H, Gao Y. Heat transfer characteristics of refrigerant-based nanofluid flow boiling inside a horizontal smooth tube. International Journal of Refrigeration. 2009;32:1259-70.

[29] Henderson K, Park Y-G, Liu L, Jacobi AM. Flow-boiling heat transfer of R-134abased nanofluids in a horizontal tube. International Journal of Heat and Mass Transfer. 2010;53:944-51.

[30] Bobbo S, Fedele L, Fabrizio M, Barison S, Battiston S, Pagura C. Influence of nanoparticles dispersion in POE oils on lubricity and R134a solubility. International Journal of Refrigeration. 2010;33:1180-6.

[31] Kedzierski MA. Effect of concentration on R134a/A12O3 nanolubricant mixture boiling on a reentrant cavity surface. International Journal of Refrigeration. 2015;49:36-48.

[32] Bashirnezhad K, Rashidi MM, Yang Z, Bazri S, Yan W-M. A comprehensive review of last experimental studies on thermal conductivity of nanofluids. Journal of Thermal Analysis and Calorimetry. 2015.

[33] Pak BC, Cho YI. Hydrodynamic and heat transfer study of dispersed fluids with submicron metallic oxide particles. Experimental Heat Transfer. 1998;11:151-70.

[34] Gleiter H. Nanocrystalline materials. progress in Materials Science. 1989;33:223315.

[35] Paul G, Philip J, Raj B, Das PK, Manna I. Synthesis, characterization, and thermal property measurement of nano-A195Zn05 dispersed nanofluid prepared by a twostep process. International Journal of Heat and Mass Transfer. 2011;54:3783-8.

[36] Krishna Sabareesh R, Gobinath N, Sajith V, Das S, Sobhan CB. Application of $\mathrm{TiO}_{2}$ nanoparticles as a lubricant-additive for vapor compression refrigeration systems - An experimental investigation. International Journal of Refrigeration. 2012;35:1989-96.

[37] Alawi OA, Sidik NAC, Mohammed HA. A comprehensive review of fundamentals, preparation and applications of nanorefrigerants. International Communications in Heat and Mass Transfer. 2014;54:81-95.

[38] Youbi-Idrissi M, Bonjour J. The effect of oil in refrigeration: Current research issues and critical review of thermodynamic aspects. International Journal of Refrigeration. 2008;31:165-79.

[39] Mahlia TMI, Saidur R. A review on test procedure, energy efficiency standards and energy labels for room air conditioners and refrigerator-freezers. Renewable and Sustainable Energy Reviews. 2010;14:1888-900.

[40] Mahbubul IM, Fadhilah SA, Saidur R, Leong KY, Amalina MA. Thermophysical properties and heat transfer performance of $\mathrm{Al}_{2} \mathrm{O}_{3} / \mathrm{R}-134 \mathrm{a}$ nanorefrigerants. International Journal of Heat and Mass Transfer. 2013;57:100-8.

[41] Xing M, Wang R, Yu J. Application of fullerene C60 nano-oil for performance enhancement of domestic refrigerator compressors. International Journal of Refrigeration. 2014;40:398-403. 
[42] Hu ZS, Lai R, Lou F, Wang L, Chen Z, Chen G, et al. Preparation and tribological properties of nanometer magnesium borate as lubricating oil additive. Wear. 2002;252:370-4.

[43] Keblinski P, Phillpot S, Choi S, Eastman J. Mechanisms of heat flow in suspensions of nano-sized particles (nanofluids). International journal of heat and mass transfer. 2002;45:855-63.

[44] Bi S, Guo K, Liu Z, Wu J. Performance of a domestic refrigerator using $\mathrm{TiO}_{2}$ R600a nano-refrigerant as working fluid. Energy Conversion and Management. 2011;52:733-7.

[45] Subramani N, Prakash M. Experimental studies on a vapour compression system using nanorefrigerants. International Journal of Engineering, Science and Technology. 2011;3:95-102.

[46] Kumar DS, Elansezhian R. Experimental study on $\mathrm{Al}_{2} \mathrm{O}_{3}-\mathrm{R} 134$ a nano refrigerant in refrigeration system. International Journal of Modern Engineering Research. 2012;2:3927-9. 